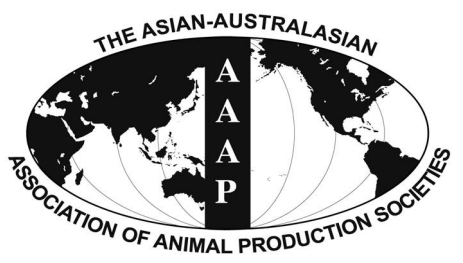

Open Access

Asian Australas. J. Anim. Sci.

Vol. 28, No. 10 : 1512-1518 October 2015

http://dx.doi.org/10.5713/ajas.14.0819

Www.ajas.info

pISSN 1011-2367 elSSN 1976-5517

\title{
The Effects of Gilts Housed Either in Group with the Electronic Sow Feeding System or Conventional Stall
}

\author{
J. C. Jang, S. W. Jung, S. S. Jin, S. J. Ohh ${ }^{1}$, J. E. Kim ${ }^{2}$, and Y. Y. Kim* \\ Department of Agricultural Biotechnology, College of Animal Life Sciences, \\ Seoul National University, Seoul 151-921, Korea
}

\begin{abstract}
This experiment was conducted to assess the welfare and productivity of gestating gilts in groups with the electronic sow feeding (ESF) system compared to conventional stalls. A total of 83 gilts (Yorkshire $\times$ Landrace) were housed into individual stalls to be artificially inseminated. Gilts confirmed pregnant were introduced to their treatment, conventional stalls (ST) or groups with the ESF system. All gilts were taken to the farrowing crates one week prior to their expected farrowing date. In the gestation period, there were no significant differences between gilts allocated to ST and ESF on growth performance. However, backfat thickness gain $(p=0.08)$ and body condition score $(\mathrm{BCS})$ at 110 days of gestation $(\mathrm{p}=0.10)$ tended to be higher in ESF gilts than ST. Likewise, gilts housed in group showed significantly higher estimated body muscle contents at 110 days of gestation $(p=0.02)$ and body muscle change during gestation $(p=0.01)$. There was a trend for a shorter parturition time in ESF gilts $(p=0.07)$. In the lactation period, group housed gilts showed a tendency to increased BCS changes $(p=0.06)$. Reproductive performance did not differ with the exception of piglet mortality $(\mathrm{ST}=0.2$ no. of piglets vs ESF $=0.4$ no. of piglets; $\mathrm{p}=0.01)$. In blood profiles, ST gilts showed a higher cortisol level at 110 days of gestation $(p=0.01)$. Weaning to estrus interval was shorter in gilts housed in ESF than ST $(p=0.01)$. In locomotory behaviors, ESF gilts recorded a tendency to elevate locomotion score at 36,70 , and 110 days of gestation $(p=0.07, p=0.06$, and $p=0.06$, respectively). Similarly, ESF gilts showed significantly higher incidence of scratches at 36, 70, and 110 days of gestation $(p=0.01)$. Moreover, farrowing rates were higher in stall treatment (97.6\%) compare to group housing treatment $(95.2 \%)$. In conclusion, while group housed gilts with ESF system positively affected welfare status in combination with less physiologically stressful environments and activity, it negatively effects piglet mortality, farrowing rates and injuries of gilts. (Key Words: Electronic Sow Feeding, Stall, Gilts, Gestation, Piglets, Group Housing)
\end{abstract}

\section{INTRODUCTION}

The European Union legislated to phase out housing pregnant sows in stalls by January 2013 due to animal welfare issues (Council Directives 91/630/EEC and 2001/88/EC, and Commission Directive 2001/93/EF). This ordinance influenced the strategies of management, feeding and sow welfare. The move towards group housing systems

\footnotetext{
* Corresponding Author: Y. Y. Kim. Tel: +82-2-878-5838, Fax: +82-2-878-5839, E-mail: yooykim@snu.ac.kr

${ }^{1}$ College of Animal Life Science, Kangwon National University, Chuncheon 200-701, Korea.

2 National Institute of Animal Science, Rural Development Administration, Cheonan 331-801, Korea.

Submitted Oct. 21, 2014; Revised Dec. 15, 2014; Accepted Apr. 30, 2015
}

has been investigated for the past two decades by European countries. Nevertheless, most Asian countries are still using stall housing because of the ease of artificial insemination, low capital cost, individual feeding and minimize aggressive behavior. However, stall housing causes a negative effect on muscle weight and bone strength (Marchant and Broom, 1996), decubital ulcers, chronic disease and stereotypes, which probably indicate poor welfare of sow (Scientific Veterinary Committee, 1997).

Sows housed in groups are known to resolve these problems. Several studies have reported the effects of group housing. In productivity, group housed sows with the electronic sow feeding (ESF) system have similar or improved productivity than sows housed in stalls (Bates et al., 2003). In peripheral physiologic measures, several 
studies have concluded that no difference in stress-related serum cortisol concentrations are evident between sows housed in stalls and those housed in groups (Barnett et al., 1989; von Borell et al., 1992; Zanella et al., 1998). However, there is limited data on the effects of group housed gilts on the measurements that are given above. Thus, more studies that compare different indicators of welfare as well as productivity in stalls and modern commercial group housing system of gilts are needed.

Therefore, the object of the study is designed to assess the adequacy of the welfare and productivity of gestating gilts housed in either conventional stalls or group housed with the ESF system.

\section{MATERIALS AND METHODS}

\section{Experimental animal management and diets}

A total of 83 gilts (Yorkshire $\times$ Landrace) with an average $180 \mathrm{~d}$ of age and approximately $134.3 \mathrm{~kg}$ of body weight $(\mathrm{BW})$ were introduced into stalls to be artificially inseminated. They were given twice daily boar contact. When signs of first estrus were detected, artificial insemination (AI) was served twice a day at 12 hour intervals with fresh diluted semen (Darby A.I. center, Anseong, Korea). Pregnancy diagnoses were done with ultrasound analyzer (Easy Scan, Dong-Jin BLS Co., Ltd., Gwangju, Korea) with day 28 and 35 postcoitum. Gilts confirmed pregnant were allotted to their treatment, ST or ESF on the basis of BW and backfat thickness (BFT) in a completely randomized design. Two gilts in ST and one gilt in ESF were excluded in the experiment because of miscarriage and failure in adaptation of feeding station during gestation, respectively. After 110 days of gestation, gilts were all moved to farrowing crate $\left(2.50 \times 1.80 \mathrm{~m}^{2}\right)$. Live body weight, body length and body condition score (BCS) were measured at mating, $110 \mathrm{~d}$ of gestation, farrowing, and $21 \mathrm{~d}$ of lactation, respectively. BFT was measured at the $\mathrm{P}_{2}$ position (mean value from both sides of the last rib and $65 \mathrm{~mm}$ away from the backbone) using Ultra-sound (Lean-meter, Renco Corp., Minneapolis, MN, USA) at the same time. Muscle and protein composition changes during gestation of primiparous sows were calculated using the equations of Dourmad et al. (1996) and Dourmad et al. (1997), respectively.

$$
\begin{aligned}
& \text { Muscle }(\mathrm{kg})=-9.2+0.61( \pm 0.052) \mathrm{BW}-0.86( \pm 0.29) \mathrm{BFT} \\
& \text { Protein }(\mathrm{kg})=2.28+(0.178 \times \mathrm{EBW})-(0.333 \times \mathrm{BFT})
\end{aligned}
$$

*EBW $(\mathrm{kg})=$ sow empty live weight estimated from the live weight $\left(=0.905 \times \mathrm{BW}^{1.013}\right)$

The reproduction traits were recorded within $24 \mathrm{~h}$ postpartum, including the number of piglets born alive, stillborn piglets, mummies, and piglet losses. Individual piglet weight of total born was measured at birth and piglets were weighed at $21 \mathrm{~d}$ of lactation. Full-HD camcorders (HMX-M20BD, Samsung, Suwon, Korea) were installed to record the duration of parturition which defined as the time between the expulsion of the first and the last born piglet. Average daily feed intake (ADFI) was scored during lactation. Detection of weaning to estrus interval (WEI) of each sow was monitored from 3 to $10 \mathrm{~d}$ after weaning.

All experimental gilts were fed daily around 08:00 h with a commercial diet during gestation and lactation and gilts in both treatments were provided $2.0 \mathrm{~kg} / \mathrm{d}$ during gestation and were ad libitum in lactation.

\section{Animal housing}

Gilts in stall treatment were housed in individual gestation stall $\left(2.15 \times 0.6 \mathrm{~m}^{2} / \mathrm{sow}\right)$ and an individual feeder with one waterer per sow. Floors were fully slatted concrete with no bedding. A climate computer regulated ventilation and heating in the compartments. Temperatures varied between $15^{\circ} \mathrm{C}$ and $20^{\circ} \mathrm{C}$. Lighting was provided in combination with a several windows and fluorescent lights, which were switched on at 08:00 $\mathrm{h}$ and switched off at 20:00 h.

Gilts in ESF treatment were housed in a room (15.2 $\mathrm{m} \times 10.2 \mathrm{~m}, 3.8 \mathrm{~m}^{2} /$ head) with full concrete flooring and approximately $10 \mathrm{~cm}$ deep rice hull bedding. The Rice hulls were provided around lying area and changed every 2 weeks. Water was provided ad libitum by 5 nipple drinkers per pen. The ESF station (Compident VII, Schauer, Prambachkirchen, Austria) was located in the middle of each pen. Gilts were identified by radio-Frequency Identification tag and provided the allocated amount of feed individually. Feed was dispensed with water in the ESF so that gilts finished consuming feed without leaving the ESF to drink water.

\section{Skin injuries and locomotion score}

Skin injuries and locomotion scores were assessed in both treatments on each of d 36, 70, and 110 as described by Karlen et al. (2007). Injuries were categorized according by fresh scratches and partially healed injuries. Each side of the gilt's body was divided into 21 areas for injury scoring. The same experimenters did scoring of all injuries in each experiment. Locomotion score was assessed based on the observation of sows standing, walking. Gilts were observed by two experimenters and given a score of 0 (not lame) to 3 (severely lame, cannot stand) while they walked on the solid concrete floor of the $50 \mathrm{~m}$ long central corridor.

\section{Sample collection and chemical analyses}

Five primiparous sows in each treatment were used to 
collect blood samples. Blood samples were collected from jugular vein at $24 \mathrm{~h}$ and $21 \mathrm{~d}$ postpartum with ethylenediaminetetraacetic acid tubes (BD Vacutainer K2E, Becton Dickinson, Plymouth, UK). Blood samples were centrifuged at $3,000 \mathrm{~g}$ at $4^{\circ} \mathrm{C}$ for $15 \mathrm{~min}$ (Eppendorf centrifuge 5810R, Hamburg, Germany) to separate plasma.

\section{Statistical analysis}

The data of the test were compared using Student's Ttest of SAS (version 9.2, 2008). Main effect in the model was different housing system. Individual gilt was considered as the experimental unit and all values are reported as least square means. Differences and suggestive differences between stall and ESF systems were considered at $p<0.05$ and $p<0.10$, respectively. The alpha level used for determination of statistical significance was 0.05 .

\section{RESULTS}

The effects of different housing systems of gilts on growth performance during gestation are presented in Table 1. There were no significant differences in BW, BFT, body length and BCS. However, ESF treatment tended to gain more BFT $(p=0.08)$ and show higher BCS $(p=0.10)$ at 110 days of gestation. Additionally, there were significant differences in the body composition changes of muscle (Table 2). The ESF gilts showed higher weight of muscle in the body $(\mathrm{p}=0.02)$ than ST gilts at 110 days, and consequently affected changes in body composition of muscle during gestation $(\mathrm{p}=0.01)$. However, no

Table 1. The effects of different housing system on growth performance of gilts in gestation

\begin{tabular}{|c|c|c|c|c|}
\hline \multirow{2}{*}{ Criteria } & \multicolumn{2}{|c|}{ Treatment } & \multirow{2}{*}{ SEM } & \multirow{2}{*}{ p-value } \\
\hline & Stall & Group & & \\
\hline No. of gestation sows & 41 & 42 & & \\
\hline \multicolumn{5}{|l|}{ Live body weight (kg) } \\
\hline At mating & 136.0 & 132.4 & 0.87 & 0.44 \\
\hline 110 days of gestation & 185.8 & 189.6 & 1.20 & 0.40 \\
\hline Gain (0 to $110 \mathrm{~d})$ & 49.6 & 57.2 & 0.92 & 0.12 \\
\hline \multicolumn{5}{|l|}{ Backfat thickness (mm) } \\
\hline At mating & 21.5 & 18.8 & 0.45 & 0.84 \\
\hline 110 days of gestation & 23.4 & 22.2 & 0.40 & 0.18 \\
\hline Gain $(0$ to $110 \mathrm{~d})$ & 1.9 & 3.4 & 0.38 & 0.08 \\
\hline \multicolumn{5}{|l|}{ Body condition score } \\
\hline At mating & 3.1 & 3.1 & 0.04 & 0.91 \\
\hline 110 days of gestation & 3.2 & 3.3 & 0.03 & 0.10 \\
\hline Gain $(0$ to $110 \mathrm{~d})$ & 0.1 & 0.2 & 0.05 & 0.11 \\
\hline \multicolumn{5}{|l|}{ Body length (cm) } \\
\hline At mating & 114.9 & 115.0 & 0.39 & 0.28 \\
\hline 110 days of gestation & 122.5 & 124.3 & 0.47 & 0.87 \\
\hline Gain $(0$ to $110 \mathrm{~d})$ & 7.6 & 9.3 & 0.43 & 0.35 \\
\hline
\end{tabular}

Table 2. The effects of different housing system on estimated body protein and muscle composition

\begin{tabular}{lcccc}
\hline \multirow{2}{*}{ Criteria } & \multicolumn{2}{c}{ Treatment } & \multirow{2}{*}{ SEM } & p-value \\
\cline { 2 - 3 } & Stall & Group & & \\
\hline Gestation No. of sows & 41 & 42 & & \\
Body protein contents $(\mathrm{kg})$ & & & & \\
$\quad$ At mating & 18.5 & 18.8 & 0.19 & 0.50 \\
$\quad 110$ days of gestation & 27.1 & 27.6 & 0.23 & 0.32 \\
$\quad$ Gain $(0$ to $110 \mathrm{~d})$ & 8.6 & 8.8 & 0.17 & 0.62 \\
Body muscle contents $(\mathrm{kg})$ & & & & \\
$\quad$ At mating & 55.4 & 55.4 & 0.60 & 0.96 \\
$\quad 110$ days of gestation & 84.0 & 87.4 & 0.75 & 0.02 \\
$\quad$ Gain $(0$ to $110 \mathrm{~d})$ & $28.6^{\mathrm{b}}$ & $31.9^{\mathrm{a}}$ & 0.60 & 0.01 \\
\hline
\end{tabular}

SEM, standard error of mean.

a,b Values with different superscripts in the same row are significantly $(\mathrm{p}<0.01)$.

improvement of changes in body protein deposition was detected. During lactation, different housing systems did not affect BW, BFT, and BCS (Table 3). Although there were no significant difference in daily feed intake, ESF gilts tended to lose more BCS ( $\mathrm{p}=0.06$ ) than ST gilts during overall lactation. Reproductive performance of sows such as the number of total born, born alive, stillbirth, mummy, mortality and weaning pigs are presented in Table 4. Mortality was higher in ESF treatments $(p=0.01)$, but there were no significant difference in the others. Litter and piglet weight also was not affected by different housing systems. Gilts housed in groups tended to shorten parturition time ( $p$ $=0.07$ ) and significantly shorten the average WEI ( $p=$ $0.01)$. Skin injuries and locomotion scores are presented in Table 5. There was a tendency for a higher locomotion score at 36, 70, and 110 days of gestation in group housed gilts $(\mathrm{p}=0.07, \mathrm{p}=0.06$, and $\mathrm{p}=0.06$, respectively).

Table 3. The effects of different housing system on body changes in lactation

\begin{tabular}{lcccc}
\hline \multirow{2}{*}{ Criteria } & \multicolumn{2}{c}{ Treatment } & \multirow{2}{*}{ SEM } & p-value \\
\cline { 2 - 3 } & Stall & Group & & \\
\hline $\begin{array}{l}\text { No. of lactation sows } \\
\text { Live body weight }(\mathrm{kg})\end{array}$ & 40 & 40 & & \\
24 h postpartum & 166.7 & 174.1 & 1.21 & 0.44 \\
21 days of lactation & 161.6 & 162.8 & 1.13 & 0.27 \\
Changes (0 to 21 d) & -5.1 & -11.3 & 0.92 & 0.25 \\
Backfat thickness (mm) & & & & \\
24 h postpartum & 21.7 & 22.2 & 0.41 & 0.63 \\
21 days of lactation & 18.6 & 19.8 & 0.37 & 0.96 \\
Changes (0 to 21 d) & -3.1 & -2.4 & 0.23 & 0.97 \\
Body condition score & & & & \\
24 h postpartum & 3.0 & 3.0 & 0.03 & 0.76 \\
21 days of lactation & 2.8 & 2.7 & 0.03 & 0.96 \\
Changes (0 to 21 d) & -0.2 & -0.3 & 0.03 & 0.06 \\
Daily feed intake $(\mathrm{kg})$ & 5.4 & 5.5 & 0.07 & 0.66 \\
\hline SEM, stang
\end{tabular}

SEM, standard error of mean. 
Table 4. The effects of different housing system on reproductive performance

\begin{tabular}{|c|c|c|c|c|}
\hline \multirow{2}{*}{ Criteria } & \multicolumn{2}{|c|}{ Treatment } & \multirow{2}{*}{ SEM } & \multirow{2}{*}{ p-value } \\
\hline & Stall & Group & & \\
\hline No. sows & 40 & 40 & & \\
\hline \multicolumn{5}{|l|}{ Litter size, no. of piglets } \\
\hline Total born & 11.4 & 11.5 & 0.24 & 0.86 \\
\hline Stillbirth & 0.7 & 0.6 & 0.11 & 0.62 \\
\hline Mummy & 0.1 & 0.1 & 0.04 & 0.17 \\
\hline Born alive & 10.6 & 10.8 & 0.25 & 0.42 \\
\hline After cross-fostering ${ }^{1}$ & 10.3 & 11.0 & 0.11 & 0.81 \\
\hline Mortality & $0.2^{\mathrm{b}}$ & $0.4^{\mathrm{a}}$ & 0.11 & 0.01 \\
\hline Weaning pigs & 10.1 & 10.6 & 0.11 & 0.86 \\
\hline Parturition time (min) & 199.5 & 187.0 & 5.44 & 0.07 \\
\hline WEI (d) & $6.3^{\mathrm{a}}$ & $6.0^{\mathrm{b}}$ & 0.15 & 0.01 \\
\hline \multicolumn{5}{|c|}{ Litter weight on lactation $(\mathrm{kg})$} \\
\hline At birth & 15.6 & 16.3 & 0.35 & 0.11 \\
\hline After cross-fostering ${ }^{1}$ & 14.5 & 16.2 & 0.29 & 0.13 \\
\hline $21 \mathrm{~d}$ & 53.3 & 54.4 & 0.90 & 0.62 \\
\hline Weight gain ( 0 to $21 \mathrm{~d}$ ) & 38.8 & 38.2 & 0.80 & 0.99 \\
\hline \multicolumn{5}{|c|}{ Piglet weight on lactation $(\mathrm{kg})$} \\
\hline At birth & 1.37 & 1.44 & 0.023 & 0.83 \\
\hline After cross-fostering ${ }^{1}$ & 1.41 & 1.49 & 0.026 & 0.08 \\
\hline $21 \mathrm{~d}$ & 5.29 & 5.16 & 0.078 & 0.75 \\
\hline Weight gain ( 0 to $21 \mathrm{~d}$ ) & 3.88 & 3.67 & 0.071 & 0.82 \\
\hline
\end{tabular}

SEM, standard error of mean; WEI, weaning to estrus interval.

${ }^{1}$ After cross-fostering day at $\mathrm{d} 1$ postpartum.

${ }^{a, b}$ Values with different superscripts in the same row are significantly $(\mathrm{p}<0.01)$.

Similarly in risk of injury, ESF gilts showed higher incidence of scratches at 36,70 , and 110 days of gestation $(\mathrm{p}<0.01)$. In addition, stall housed gilts observed more farrowing rates $(97.6 \%)$ than ESF gilts $(95.2 \%)$. In serum cortisol, ST gilts showed significantly higher levels of cortisol $(p=0.01)$ at 110 days of gestation and a tendency $(p=0.08)$ on 24 hours postpartum (Table 6$)$.

\section{DISCUSSION}

Different housing systems did not show any significant differences on growth performance of gilts. However, BFT gain $(p=0.08)$ and BCS at 110 days of gestation $(p=0.10)$ tended to increase in gilts housed in groups. Similar results are shown in several studies. Weng et al. (2009) reported that gilts housed in groups showed significantly higher BTF gain than those housed in stalls due to different thermal environment experienced by animals. Marchant and Broom (1996) reported that although BW and body length are heavier and similar compare to group housed with ESF as gilts, group housed sows show significantly heavier and longer by the fourth parity. Possible explanations for these results are associated with muscular and skeletal development by activity (Marchant and Broom, 1996), less
Table 5. The effects of different housing system on skin injuries and locomotion score

\begin{tabular}{|c|c|c|c|c|}
\hline \multirow{2}{*}{ Criteria } & \multicolumn{2}{|c|}{ Treatment } & \multirow{2}{*}{ SEM } & \multirow{2}{*}{ p-value } \\
\hline & Stall & Group & & \\
\hline \multicolumn{5}{|c|}{ Incidence of scratch, No./gilt } \\
\hline Initial & 0.6 & 0.7 & 0.09 & 0.50 \\
\hline 36 days of gestation & $2.9^{\mathrm{b}}$ & $16.2^{\mathrm{a}}$ & 0.91 & 0.01 \\
\hline 70 days of gestation & $2.6^{\mathrm{b}}$ & $6.2^{\mathrm{a}}$ & 0.39 & 0.01 \\
\hline 110 days of gestation & $1.1^{\mathrm{b}}$ & $4.0^{\mathrm{a}}$ & 0.26 & 0.01 \\
\hline \multicolumn{5}{|l|}{ Locomotion score } \\
\hline 36 days of gestation & 0.317 & 0.595 & 0.0772 & 0.07 \\
\hline 70 days of gestation & 0.561 & 0.810 & 0.0662 & 0.06 \\
\hline 110 days of gestation & 0.585 & 0.857 & 0.0713 & 0.06 \\
\hline
\end{tabular}

performing energetically costly stereotypes (Cronin, 1985), and decreasing lower critical temperature (LCT) by providing bedding materials (Geuyen et al., 1984). Indeed, sows that had a higher LCT require a higher proportion of their energy intake to maintain body temperature (King, 1991). Karlen et al. (2007) suggested that sows confined in stalls show poorer body condition as a consequence of their higher LCT. In agreement with previous studies, our findings indicated that activity and thermoregulation might be attributed to improve BFT and BCS in group housed gilts.

Different housing systems significantly influenced the estimated body composition. The lack of exercise in stalls leads to smaller locomotor muscles in proportion to total body weight than group housed sows (Marchant and Broom, 1996). This is consistent with the study of Petersen et al. (1998) who confirmed that sows reared in large pens had an increased total bone mass, most significantly for the leg, compared to that of stall sows. Although our experiment did not conduct a postmortem examination, results of the

Table 6. The effects of different housing system on serum cortisol concentration

\begin{tabular}{lcccc}
\hline \multirow{2}{*}{ Criteria } & \multicolumn{2}{c}{ Treatment } & \multirow{2}{*}{ SEM } & \multirow{2}{*}{ p-value } \\
\cline { 2 - 3 } & Stall & Group & & \\
\hline Cortisol $(\mu \mathrm{g} / \mathrm{dL})$ & & & & \\
Sow & & & & \\
$\quad$ At breeding & 2.44 & 4.75 & 0.611 & 0.36 \\
$\quad 110$ days of gestation & $4.48^{\mathrm{a}}$ & $3.00^{\mathrm{b}}$ & 0.424 & 0.01 \\
24 h postpartum & 5.60 & 3.78 & 0.613 & 0.08 \\
$\quad$ 21 days of lactation & 2.76 & 3.86 & 0.363 & 0.77 \\
Piglet & & & & \\
$\quad$ At birth & 8.72 & 5.98 & 1.018 & 0.54 \\
$\quad 21$ day & 5.38 & 5.28 & 0.566 & 0.17 \\
\hline
\end{tabular}

SEM, standard error of mean.

${ }^{\mathrm{a}, \mathrm{b}}$ Values with different superscripts in the same row are significantly $(\mathrm{p}<0.01)$. 
present study indicated that activity would be a contributing factor affecting the growth of muscle mass in group housed gilts.

There were few differences in BW and BFT changes between the two gestation housing treatments. Our results are in agreement with Bohnenkamp et al. (2013), but differ from Borell et al. (1992) who reported that gilts housed in groups showed significantly less BFT loss during lactation. The sows mobilize their body reserves and enhance their feed intake (Eissen et al., 2000) to increase energy demand during lactation. However, considering there were no statistical differences on ADFI in our results, we could explain that the tendency of poorer BCS in group housed gilts $(p=0.06)$ were associated with higher loss of BW and BFT.

In reproductive performance, piglet mortality was significantly increased $(p<0.01)$ in group housed treatment, which is in agreement with the results of Cronin et al. (1996). A dominant portion of piglet mortality in both treatments was crushing (Stall, 91\%; ESF, 89\%) in the present experiment. One explanation for this result may be the maladjustment of confinement. Boyle et al. (2002) found that sows group-housed during gestation had more postural changes, more ventral and lateral lying and dog sitting behaviors than sows from stalls. This implies that allowing sows to move restlessly increase the incidence of piglet crushing. This agrees with previous studies that group gestation housing may have a negative influence on sow welfare when these sows are placed in farrowing stalls (Mcglone et al., 2004), resulting in an increased number of stillborn piglets, and an increased risk of pre-weaning mortality (Weary et al., 1996), and possibly a disruption in the nursing cycle between sow and litter (Spinka et al., 1997).

Some previous studies calculated the duration of farrowing in sows and found that the average farrowing period ranged from 156 to 262 minutes (Van Dijk et al., 2005). Both treatments recorded in the range of value found in previous studies, but there was a trend towards prolonged parturition length in stall treatment $(\mathrm{p}=0.07)$. Parturition appears to be dependent on high concentrations of oxytocin, and has been shown to be slowed or prevented when plasma oxytocin concentration is reduced by treatment with opioid (Russell et al., 1989). Chronic environmental stress activates endogenous opioid pathways that inhibit oxytocin secretion and thereby prolong delivery (Lawrence et al., 1994). Likewise, the present result indicates that prolonged delivery in stall housed gilts was caused by a chronic stressful environment, resulting in dysfunction of the endocrine regulation.

Group housed primiparous sows significantly showed shorter WEI $(\mathrm{p}<0.01)$. Previous experiments have shown the effects of different housing systems on WEI of sows. However, the results have not always been concordant. Group housing did not affect WEI (Schmidt et al., 1985). In contrast, there was an increase in the number of gilts exhibiting irregular estrus behavior in stalls (Ford and Christenson, 1979; Rampacek et al., 1984). Moreover, Weng et al. (2009) reported that gilts housed in conventional gestating stalls and farrowing crates observed the significantly longest WEI than group housed gilts. This implies that confinement stress in stall housed gilts is affected negatively, but positively in group housing gilts by releasing more estrus-stimulating hormones.

In previous studies, aggressive incidents, queuing and many non-feeding visits have been well recognized as being present when using ESF feeders for gestating sows (Jensen et al., 2000). However, less comparative studies have been conducted between stall and group housing on health status. The occurrence of skin injuries in group housed sows is a direct result of aggressive behavior. Previous studies suggest that aggression decreased with less frequent regrouping due to a decreased demand for the establishment of new rank relationships (Hunter and Smith, 1991). In contrast, individually housed sows can be protected from aggressive physical interactions if partitions are in place (McGlone et al., 2004). In the present study, group housing treatments showed significantly higher skin scratches in all phases $(p<0.01)$. This implies that although the static group is well recognized social hierarchy and highly familiar with each of gilts, they encounter higher aggressiveness around feeding machine.

On the other hand, the tendency toward deterioration of locomotion scores in group housed gilts in 35, 70, and 110 days of gestation $(\mathrm{p}=0.07, \mathrm{p}=0.06$, and $\mathrm{p}=0.06$, respectively) might be associated with in combination of aggression at every feeding time and floor conditions. Several studies have conducted the effects of beddings in group housing. Andersen et al. (1999) found that in group housed sows, the supply of a bedding substrate reduced the frequency of abnormal gait, compared to sows raised on a slatted floor. Moreover, group housing with straw bedding is almost always associated with large, dynamic groups and ESF feeding (Spoolder et al., 2009). Thus, enrichment and bedding may be an effective way in large group sizes to reduce incidences of aggression. However in our experiment, rice hulls were provided only around the lying area, considering slurry systems as well as ease of purchase compare to straw. Thus, the ESF system would be less advantageous regarding leg injuries and longevity for group housing.

Different housing systems affect farrowing rates, however results are still inconsistent. According to previous studies, farrowing performance and longevity of sows in 
dynamic and static groups in an ESF system did not differ (Anil et al., 2006). In contrast, farrowing rate was $10 \%$ lower in group housing sows compare to stall housing (Karlen et al., 2007). In our findings, Stall housed gilts showed higher farrowing rates $(97.6 \%)$ than that of ESF gilts $(95.2 \%)$. Possible reason for this can be explained by attribution of continuous fighting, resulting higher risk of injuries as well as leg problems.

Generally, a poor welfare situation could lead to extreme stress to animals. Blood cortisol concentrate has been the most common physiological parameter used to measure farm animal welfare (Terlouw et al., 1997), although the measurement suffers from diurnal variations and sample collection artifacts (McGlone et al., 2004). Barnett et al. (1989) reported that sows housed in stalls had a moderate, but statistically significant increase in cortisol concentrations compared with group-housed sows. In addition, Broom et al. (1995) reported similar concentrations of cortisol for stall-and group-housed sows. Recently, a meta-analysis of 35 refereed journal articles by McGlone et al. (2004) reported that the average stereotypes, cortisol, and immune function are statistically similar between sows in stalls versus group pens. In the present study, stall housed gilts showed significantly higher serum cortisol concentration in 110 days of gestation $(p<0.01)$ and tendency in 24 hours postpartum $(\mathrm{p}=0.08)$. Possible explanation for this result is that the chronic stress stem from confinement in stalls negatively influenced the growth of gilts in gestation. There was evidence that gilts in stalls had less BFT gain and BCS change. Moreover, prolonged parturition length in stall treatment was associated with increased serum cortisol concentration in 24 hours postpartum.

\section{IMPLICATIONS}

A modern type group housed gilts resulted in several possibilities for welfare parameters. Physiologically, group housed gilts lead to an enhancement of more accumulation of backfat as well as better muscle content in the body. On the other hand, several problems have remained in electronic sow feeding system. Advanced management or facilities for reducing piglet mortality are needed in order to ameliorate productivity. Additionally, further investigations are needed for managing aggressive behavior, following an increase of feet and leg problems, which is closely related to longevity of gilts as well as economic losses of the farm.

\section{ACKNOWLEDGMENTS}

This study was supported by Rural Development Administration (RDA; Project No. PJ009226), Republic of Korea.

\section{REFERENCES}

Andersen, I. L., K. E. Bøe, and A. L. Kristiansen. 1999. The influence of different feeding arrangements and food type on competition at feeding in pregnant sows. Appl. Anim. Behav. Sci. 65:91-104.

Barnett, J. L., P. H. Hemsworth, E. A. Newman, T. H. Mc Callum, and C. G. Winfield. 1989. The effect of design of tether and stall housing on some behavioural and physiological responses related to the welfare of pregnant pigs. Appl. Anim. Behav. Sci. 24:1-12.

Bates, R. O., D. B. Edwards, and R. L. Korthals. 2003. Sow performance when housed either in groups with electronic sow feeders or stalls. Livest. Prod. Sci. 79:29-35.

Bohnenkamp A. L., C. Meyer, K. Müller, and J. Krieter. 2013. Group housing with electronically controlled crates for lactating sows. Effect on farrowing, suckling and activity behavior of sows and piglets. Appl. Anim. Behav. Sci. 145:3743.

Boyle, L. A., F. C. Leonard, P. B. Lynch, and P. Brophy. 2002. Effect of gestation housing on behaviour and skin lesions of sows in farrowing crates. Appl. Anim. Behav. Sci. 76:119-134.

Broom, D. M., M. T. Mendl, and A. J. Zanella. 1995. A comparison of the welfare of sows in different housing conditions. Anim. Sci. 61:369-385.

Cronin, G. M. 1985. The Development and Significance of Abnormal Stereotyped Behaviours in Tethered Sows. Ph.D. Thesis, Wageningen Agricultural University, Wageningen, Netherlands.

Cronin, G. M., G. J. Simpson, and P. H. Hemsworth. 1996. The effects of the gestation and farrowing environments on sow and piglet behaviour and piglet survival and growth in early lactation. Appl. Anim. Behav. Sci. 46:175-192.

Dourmad, J. Y., M. Etienne, and J. Noblet. 1996. Reconstitution of body reserves in multiparous sows during pregnancy: Effect of energy intake during pregnancy and mobilization during the previous lactation. J. Anim. Sci. 74:2211-2219.

Dourmad, J. Y., M. Etienne, and J. Noblet. 1997. Prediction de la composition chimique des truies reproductrices a partir du poids vif et de l'epaisseur de lard dorsal. J. Rech. Porcine Fr. 29:255-262.

Eissen, J. J., E. Kanis, and B. Kemp. 2000. Sow factors affecting voluntary feed intake during lactation. Livest. Prod. Sci. 64:147-165.

Ford, S. P. and R. K. Christenson. 1979. Blood flow to uteri of sows during the estrous cycle and early pregnancy: local effect of the conceptus on the uterine blood supply. Biol. Reprod. 21:617-624.

Geuyen, T. P. A., J. M. F. Verhagen, and M. W. A. Verstegen. 1984. Effect of housing and temperature on metabolic rate of pregnant sows. Anim. Prod. 38:477-485.

Jensen, K. H., L. S. Sørensen., D. Bertelsen., A. R. Pedersen., E. Jørgensen., N. P. Nielsen, and K. S. Vestergaard. 2000. Management factors affecting activity and aggression in dynamic group housing systems with electronic sow feeding: A field trial. Anim. Sci. 71:535-545.

Karlen, G. A. M., P. H. Hemsworth, H. W. Gonyou, E. Fabrega, A. D. Strom, and R. J. Smits. 2007. The welfare of gestating sows in conventional stalls and large groups on deep litter. Appl. 
Anim. Behav. Sci. 105:87-101.

King, R. 1991. The basics of sow feeding and management. In: Proceedings Saskatchewan Pork Industry Symposium, Saskatoon, Saskatchewan, Canada. pp. 47-51.

Lawrence, A. B., M. C. Appleby, and H. A. Macleod. 1988. Measuring hunger in the pig using operant conditioning: the effect of food restriction. Anim. Prod. 47:131-137.

Marchant, J. N. and D. M. Broom. 1996. Factors affecting posturechanging in loose-housed and confined gestating sows. J. Anim. Sci. 63:477-485.

McGlone, J. J., E. H. Borell, J. von Deen, A. K. Johnson, D. G. Levis, M. C. Meunier-Salaün, J. Morrow, D. Reeves, J. L. Salak-Johnson, and P. L. Sundberg. 2004. Compilation of the scientific literatures comparing housing systems for gestating sows and gilts using measures of physiology, behavior, performance and health. Prof. Anim. Sci. 20:105-117.

Petersen, V., H. B. Simonsen, and L. G. Lawson. 1995. The effect of environmental stimulation on the development of behavior in pigs. Appl. Anim. Behav. Sci. 45:215-224.

Rampacek, G. B., R. R. Kraeling, E. S. Fonda, and C. R. Barb. 1984. Comparison of physiological indicators of chronic stress in confined and nonconfined gilts. J. Anim. Sci. 58:401-408.

Russell, J. A., R. G. Gosden, E. M. Humphreys, R. Cutting, N. Fitzsimons, S. Johnston, S. Liddle, S. Scott, and J. A. Stirland. 1989. Interruption of parturition in rats by morphine: a result of inhibition of oxytocin secretion. J. Endocrinol. 121:521-536.

SAS Institute Inc. 2008. SAS Institute Inc. User's Guide (release 9.2), Cary, NC, USA.

Schmidt, W. E., J. S. Stevenson, and D. L. Davis. 1985. Reproductive traits of sows penned individually or in groups until 35 days after breeding. J. Anim. Sci. 60:755-759.
Scientific Veterinary Committee. 1997. The welfare of intensively kept pigs. In: Report of the cientific Veterinary Committee, Animal Welfare Section, to the Comission of the European Union. Doc. XXIV/ScVc/0005/1997. Adopted September 30, 1997. Brussels, Belgium.

Spinka, M., G. Illmann., B. Algers, and Z. Stetkova. 1997. The role of nursing frequency in milk production in domestic pigs. J. Anim. Sci. 75:1223-1228.

Spoolder, H. A. M., M. J. Geudeke, C. M. C. van der PeetSchwering, and N. M. Soede. 2009. Group housing of sows in early pregnancy: a review of success and risk factors. Livest. Sci. 125:1-14.

Terlouw, E. M., W. P. G. Schouten, and J. Ladewig. 1997. Physiology in Animal Welfare (Eds. C. Appleby and B.O. Hughes). CAB Int., Oxon, New York, USA. 143 p.

van Dijk, A. J., B. T. van Rens, T. van der Lende, and M. A. Taverne. 2005. Factors affecting duration of the expulsive stage of parturition and piglet birth intervals in sows with uncomplicated, spontaneous farrowings. Theriogenology 64: 1573-1590.

von Borell, E., J. R. Morris, J. F. Hurnik, B. A. Mallard, and M. M. Buhr. 1992. The performance of gilts in a new group housing system: Endocrinological and immunological functions. J. Anim. Sci. 70:2714-2721.

Weary, D. M., E. A. Pajor, D. Fraser, and A. M. Honkanen. 1996. Sow body movements that crush piglets: A comparison between two types of farrowing accommodation. Appl. Anim. Behav. Sci. 49:149-158.

Weng, R. C., S. A. Edwards, and L. C. Hsia. 2009. Effect of individual, group or ESF housing in pregnancy and individual or group housing in lactation on sow behavior. Asian Australas. J. Anim. Sci. 22:1574-1580. 